\title{
Porque dinheiro importa: a dinâmica das contribuições eleitorais para o Congresso Nacional em 2002 e 2006
}

\author{
Leany Barreiro Lemos \\ Universidade de Brasília e Universidade de Princeton \\ Daniel Marcelino \\ Universidade de Brasília e Universidade de York \\ João Henrique Pederiva \\ Universidade de Brasília e Senado Federal
}

\begin{abstract}
Resumo: Muitos trabalhos estudam a relação entre dinheiro e eleições, especialmente como o aporte de recursos pode explicar o sucesso do candidato. Nosso artigo tem como objetivo identificar aspectos do financiamento de campanha nas eleições para o Congresso Nacional brasileiro, nos anos de 2002 e 2006, com base nos dados do TSE. Buscamos captar: a) diferenças nas receitas e gastos entre candidatos à reeleição e novos candidatos; b) variações regionais, dadas as profundas clivagens socioeconômicas dos distritos eleitorais, que podem afetar as contribuições e despesas realizadas; c) variações camerais, dada a incongruência do bicameralismo brasileiro; d) variações partidárias, ou seja, se há candidatos cujas campanhas saem mais "caras" ou mais "baratas", a depender do partido politico.
\end{abstract}

Palavras-chave: financiamento de campanha; Senado; Câmara dos Deputados; eleições; Brasil

\begin{abstract}
Many scholars have written on money and elections, especially on how expenditures can explain the performance of the candidate. Our paper aims at describing some features of finance campaign for the Brazilian National Congress in 2002 and 2006, based on the Superior Electoral Court (TSE) data. We tried to capture: a) donations and expenditures variation of incumbents and challengers; b) regional variations, given the socioeconomic cleavages of the electoral district, that may affect donations and expenditures; c) cameral variations, given the incongruent character of the Brazilian bicameralism; d) party variations, that is, if there are candidates that cost "more" or "less", depending on party affiliation.
\end{abstract}

Keywords: campaign finance; Senate; Chamber of Deputies; elections; Brazil 


\section{Apresentação ${ }^{1}$}

Quanto custa uma disputa para deputado ou senador no Brasil? É mais barato sair candidato a deputado ou a senador? Existe uma relação positiva entre valor gasto na campanha e sucesso eleitoral? Um candidato que concorre à reeleição precisa de menos ou de mais recursos do que um novato? Eleger-se em São Paulo custa o mesmo, proporcionalmente, do que se eleger na Bahia ou no Acre? Concorrer a uma vaga de deputado ou senador, pelo PMDB, custa o mesmo do que pelo PSDB ou PT? Os candidatos da base governista recebem mais doações do que os da oposição? O presente artigo busca responder a essas questões que dizem respeito ao complexo quadro do financiamento eleitoral no Brasil, a partir dos dados dispostos pelo TSE para as eleições ao Senado Federal e à Câmara dos Deputados nos anos de 2002 e 2006.

Nosso artigo considera, para efeito de análise, apenas os candidatos à Câmara dos Deputados (CD) e ao Senado Federal (SF) que prestaram contas de receitas e despesas. Assim, restringe-se, em 2002, a 2.903 candidatos, sendo que 2.661 para a CD e 242 para o Senado. Em 2006, restringe-se a 3.704 candidatos, sendo 3.546 para a CD e 158 para o SF. O total dos gastos declarados pelos candidatos e partidos - volume que trabalhamos aqui - foi de pouco mais de $R \$$ 411 milhões em 2002, e R $\$ 601$ milhões em 2006, representando um aumento de cerca de $68 \%$ entre eleições.

De que forma a alteração nos valores das campanhas pode ser um tema importante para a Ciência Política brasileira? Conhecer as minúcias dos dados de financiamento é relevante, do ponto de vista analítico, porque nos permite debater sobre a relação entre dinheiro e eleições. O resultado do pleito determina o perfil da representação e do balanço do poder, especialmente no que tange a partidos políticos, regiões e minorias, e permite inferências acerca da possível influência dos doadores nas escolhas sobre políticas públicas. Assim, debates - sempre recorrentes - sobre reformas políticas que proponham mudanças no formato dos sistemas de contribuições demandam compreensão e entendimento das características e do desempenho do atual sistema².

Do ponto de vista teórico, os cientistas políticos debruçam-se, há algum tempo, sobre os efeitos e a dinâmica das contribuições financeiras em campanhas eleitorais, procurando verificar se as contribuições financeiras afetam os resultados nas urnas, ou seja, se a quantidade de recursos é traduzida em votos. Ganhou

1 Trabalho apresentado no $33^{\circ}$ Encontro Anual da ANPOCS, Caxambu, 2009. Agradecemos aos comentaristas do GT 21, especialmente a Glaucio Soares e Lucio Rennó, bem como aos pareceristas anônimos da OP.

2 Um exercício interessante seria, talvez, projetar as alterações propostas de reforma, a partir dos dados atuais, e identificar os futuros beneficiários - e assim advocates - das mudanças e os seus opositores. 
visibilidade particular o tema de como o fundraising eleitoral pode ser determinante para os candidatos com vantagem comparativa, ou seja, aqueles que concorrem à reeleição (JACOBSON, 1980; 1987; 1990; PEREIRA; RENNÓ, 2001; 2007). Entretanto, como apontado por Samuels (2001a; 2001b; 2001c), os principais argumentos que explicam a lógica da relação dinheiro-votos no sistema norteamericano parecem não funcionar tão bem para o caso brasileiro. Nos Estados Unidos, os candidatos à reeleição (incumbents) e os desafiantes que pleiteiam a ocupação dos cargos (challengers) beneficiam-se de maneira diferenciada dos recursos de campanha: os primeiros beneficiam-se menos, porque trazem uma vantagem original de seus mandatos, que reduz o impacto do financiamento eleitoral no período de campanha. Como os desafiantes são menos conhecidos, o impacto do financiamento nas suas campanhas é mais significativo. No Brasil, por sua vez, não haveria incentivos à construção de carreiras no poder legislativo, dada a centralidade do poder executivo, a adoção de um sistema eleitoral proporcional de lista aberta, a grande magnitude dos distritos, o alto número de candidatos e a baixa capacidade agregadora dos partidos (SAMUELS, 2000; LEONI, PEREIRA e RENNÓ, 2003)3. O mercado político brasileiro é, portanto, de alto risco: todos os candidatos traduziriam igualmente recursos em votos, sem a distinção, tão cara à literatura norte-americana, entre incumbents e challengers ${ }^{4}$. No Brasil, enfim, o dinheiro teria a mesmo importância para todos os candidatos.

O presente artigo desdobra-se sobre essa questão - de que "money matters", mas vai além da questão entre candidatos à reeleição (incumbents) e novatos (challengers) ${ }^{5}$. Seu principal objetivo é sistematizar os dados de campanha e buscar evidências sobre padrões de financiamento também segundo um número de variáveis regionais, partidárias e camerais. Ele está dividido em cinco seções. Após esta abertura, a próxima traz o debate mais geral sobre as relações entre doações e gastos de campanha. A terceira descreve de maneira sintética os dados e as variáveis empregadas. A descrição dos resultados e a sua análise constam da quarta seção. A quinta seção encerra com as conclusões e as sugestões de desdobramentos da pesquisa.

\footnotetext{
3 Isso significa que o debate norte-americano sobre incumbents $x$ challengers, nas eleições para deputado federal (House of Representatives), exige uma relativização para o Brasil, onde os incentivos à reeleição são baixos e há mais benefícios em outros cargos, como governador ou prefeito de grandes cidades.

4 Essa é uma discussão bastante profícua, que, todavia, vai além dos argumentos aqui simplificadamente colocados. Para mais detalhes, ver Jacobson (1990).

5 Incumbent aqui é o deputado/ senador portador de mandato e que se candidata `a reeleição; challenger (desafiante) é o candidato que não possui o mandato para o cargo a que esta concorrendo. Embora utilizemos o termo "novato" em algumas passagens, não significa que o candidato seja um amador politico: ele pode ter outro mandato (i.e., um deputado federal candidato a senador) ou ocupar cargos executivos não-eletivos.
} 


\section{O debate sobre o financiamento das campanhas}

Assumimos o pressuposto de que resultados eleitorais apresentam um claro vínculo com doações e gastos de campanha. Partimos também de bases teóricas de estudos centrados em candidatos; ou seja, para o sucesso eleitoral, são mais importantes os fatores individuais dos candidatos do que os fatores partidários (programa, ideologia) ou o desempenho na arena legislativa, numa discussão que segue os pressupostos de Fenno (2002) e Mayhew (2004) ${ }^{6}$. Grosso modo, podemos dizer que o maior interessado na vitória de cada candidato é ele mesmo (MAINWARING, 1999; AMES, 2003). Essa interpretação pode ser estendida também às doações para campanhas eleitorais, objeto deste artigo. Isso porque, como dito antes, há os efeitos da magnitude do distrito, da representação proporcional de lista aberta e da limitada capacidade de fundraising dos partidos políticos, que acirram ainda mais a disputa pelos cargos eletivos e elevam o grau da competição entre e dentro dos partidos ${ }^{7}$. Somem-se a isso o aumento do número de candidatos, o encarecimento crescente das campanhas, especialmente em face do uso das mídias, e a crônica escassez de financiadores (SAMUELS, 2001b; 2001c). Não há como desconsiderar, por conseguinte, o papel central de cada candidato: ele é o responsável pela busca das fontes dos recursos e pelo direcionamento dos gastos da sua campanha.

Por seu turno, os doadores são atores fundamentais para os processos eleitorais. Em muitos casos, determinam não só quanto dinheiro haverá nas eleições, mas também a própria seleção dos candidatos, já que muitos candidatos dependem diretamente das doações (JACOBSON, 1980). Ademais, os recursos não direcionados para os incumbents podem alimentar as campanhas dos desafiantes (MAYHEW, 2004).

Um grande avanço no debate sobre dinheiro e eleições decorreu dos trabalhos de Jacobson (1978; 1980; 1981; 1987; 1990), que percebeu uma variável-chave para explicar a variação do uso do dinheiro e dos resultados nas campanhas nos Estados Unidos: the incumbency factor (1980). Segundo Jacobson, a reeleição é a variável que mais afeta a habilidade de obtenção do dinheiro nas campanhas. Seus achados sugerem que a tarefa de conseguir recursos (fundraising) é fundamentalmente diferente entre os candidatos à reeleição e os candidatos "novatos", ou "desafiantes": "incumbency is without question the most critical variable

6 O Brasil é considerado uns dos países com índice de voto pessoal mais alto no mundo (CAREY e SCHUGART, 1995).

7 No Brasil, um dos fundamentos para a mudança de partido é o receio de que falte a indicação da legenda, na forma do diretório estadual ou local, para que o candidato concorra ao posto almejado. Por outro lado, cabe ressaltar que em determinados distritos o processo de seleção apresenta baixa competitividade. 
affecting a candidate's ability to raise money for a campaign; the entire fundraising environment is fundamentally different for incumbents and nonincumbents" (JACOBSON, 1980 p.105). Além disso, as vantagens diferenciadas entre os dois grupos de candidatos também decorrem do contexto institucional, já que o exercício da função parlamentar permite acesso a benefícios diversos (MAYHEW, 2004).

Diante de significativas vantagens, o congressista que persegue a reeleição só precisaria se prevenir dos que o desafiam, mediante o aumento dos próprios gastos. Assim, esse dinheiro será, fatalmente, um recurso mais escasso para os candidatos contestadores - que terão menos chances de ganhar - do que para os candidatos à reeleição, resultando na baixa taxa renovação do congresso (JACOBSON, p.1987). Ou seja, a diferença básica entre os dois tipos de candidaturas decorre da probabilidade de vitória dos candidatos.

As chances de um candidato à reeleição seriam, em princípio, maiores do que as do desafiante, porque deriva de vantagens anteriores (staff, franquias, ter seu nome conhecido e veiculado durante o mandato etc). Entretanto, a desvantagem do desafiante tende a desaparecer em situações em que não há competição entre antigos e novatos, mas entre apenas nomes novos (open seat). Ainda assim, devemos relativizar o argumento, posto que a taxa de renovação norte-americana é de menos de 10\%, mas, no Brasil, essa taxa, na média das eleições de 1990, 1994, 1998, 2002 e 2006, para a Câmara dos Deputados, foi de 50,5\%. O seu menor valor foi de 44\%, em 1998 (DIAP, 2009).

No Brasil, os primeiros trabalhos relacionando dinheiro e eleições são de Samuels (2001a, 2001b, 2001c). Ele foi o primeiro também a estabelecer marcos comparativos entre as campanhas no Brasil e nos Estados Unidos. Seus estudos exploraram os dados das prestações de contas dos candidatos das eleições de 1994 e 1998, disponíveis no Tribunal Superior Eleitoral - TSE. Samuels conclui que os gastos influenciam os resultados nas campanhas brasileiras: $1 \%$ de gasto adicional, referido ao valor total da campanha, no estado (o distrito eleitoral dos congressistas), aumenta em $0,5 \%$ os votos do candidato, como porcentagem do total. Além disso, ser ou não deputado (ele excluiu o Senado de seu estudo) não altera o ponto de partida: "money helps win elections in Brazil equally for incumbents and challengers", enquanto nos Estados Unidos "challengers gain more from spending than incumbents" (SAMUELS, 2001 a p.580).

Assim, o argumento de Samuels (2001a) apóia fortemente a tese de que recursos financeiros estão positivamente correlacionados com vitórias eleitorais, e que isso, percebido pelos atores, leva-os a tentar arrecadar e gastar o máximo possível, na expectativa de ganharem mais votos. A ausência da incumbency advantage nas eleições legislativas, implica que, a cada nova eleição, saem todos do mesmo patamar de disputas, a despeito de possíveis vantagens que possam ser 
auferidas pela distribuição de pork barrel (AMES, 1995).

Posteriormente, Pereira e Rennó $(2001,2007)$ também dialogaram com o tema do impacto dos gastos de campanha no sucesso eleitoral dos candidatos à Câmara dos Deputados. Em trabalho de 2007, eles revisitaram os argumentos anteriores e debateram os condicionantes do sucesso eleitoral nas eleições de 1998 e 2002. Encontram, por exemplo, que uma variável interveniente importante é o fato de o Presidente estar concorrendo à reeleição. Quanto aos gastos, revelam que, nas eleições de 1998, "quem gastou mais, obteve mais votos na eleição anterior, concentrou menos votos e mudou menos de partido, tem maior chance de ser reeleito" (PEREIRA e RENNÓ, 2007, p.22). Todavia, nas eleições de 2002, o gasto teve impacto atenuado. Diante da dificuldade de especificação de um modelo de análise para os resultados dos gastos eleitorais, Pereira e Rennó concluíram pela ineficácia explicativa do sucesso eleitoral da variável gastos de campanha. Não avançam, assim, sobre os demais efeitos eleitorais proporcionados pelo dinheiro nas campanhas.

Tais referências indicam a existência de uma rica e variada literatura sobre o papel do dinheiro nas eleições norte-americanas, em particular para o Congresso, mas uma baixa exploração do tema, no Brasil, com uma produção bibliográfica ainda pequena. Vale, então, examinar os dados agregados na busca de padrões que desvelem como se configuram as relações entre os recursos de campanha e os resultados das eleições.

\section{Os dados e as variáveis}

A partir de 1994, o Tribunal Superior Eleitoral (TSE), em conjunto com os Tribunais Regionais Eleitorais (TREs), passou a divulgar os dados das candidaturas, as informações auto-declaradas sobre o perfil dos candidatos, em todas as esferas, e também informações referentes às contas de campanha dos candidatos. Devemos frisar que os dados são de responsabilidade dos candidatos e têm sido questionados quanto à sua veracidade. Diversos escândalos apontam para o financiamento ilícito de campanha, via e.g. doações não-contabilizadas (caixa dois), que constitui crime $^{9}$. Inobstante isso, os dados disponíveis, como lembra Samuels

\footnotetext{
${ }^{8}$ Sobre esse argumento, Samuels (1998) afirma que o pork barreling não é mensurável como fator agregador de vantagem eleitoral, uma vez que os parlamentares são forçados a dividirem os créditos políticos nos sistemas de multimember district.

${ }^{9} \mathrm{O}$ presidente Lula declarou, em entrevista na França: "o caixa dois do PT era algo que é feito no Brasil sistematicamente". O vice-presidente José de Alencar, além de confessar publicamente ter se valido desse expediente para sua eleição ao Senado, em 1998, afirmou que se houvesse punição ao crime "todo mundo seria cassado" (Revista Veja 1927, de 19 de outubro de 2005). Antes disso, o publicitário Duda Mendonça havia confessado o pagamento por serviços, na campanha de Lula, em 2002, mediante depósitos clandestinos em uma conta secreta no exterior <http://veja.abril.com.br/180106/p_044.html>. Acesso em: [25 set. 2009].
} 
(2001a), trazem padrões embutidos, sem embargo do ceticismo e dos questionamentos que os cercam ${ }^{10}$.

Quanto ao custo total, na verdade, ainda não sabemos quanto custam, de fato, as eleições e as campanhas eleitorais. Segundo Samuels (2006), as campanhas no Brasil são mais caras do que as norte-americanas: três vezes mais, em termos per capita, levando-se em conta a paridade do poder de compra (PPP). Entretanto, esses custos não incluem o financiamento público indireto. Isso sem mencionar os questionamentos sobre a fidedignidade das informações prestadas à justiça eleitoral. Desde 1993, após o escândalo que culminou no impeachment do ex-Presidente Collor, ocorreram mudanças nas regras eleitorais brasileiras, para que o financiamento privado fosse mais conhecido e mensurável ${ }^{11}$. Todavia, parte do financiamento público para a manutenção da atividade política e eleitoral no País ainda permanece obscura. Sabemos quanto é repassado do fundo partidário aos partidos, anualmente, pela via orçamentária, e os recursos provenientes de multas. Contudo, pouco ou nada sabemos sobre as renúncias fiscais, associadas à propaganda política e eleitoral, no rádio e TV ${ }^{12}$, e os outros benefícios indiretos, como o uso de espaços e outros recursos públicos que não o dinheiro.

É preciso mencionar que a qualidade dos dados disponíveis tem melhorado. Desde 1994, a principal mudança introduzida foi a Instrução Normativa Conjunta SRF/TSE, de 10 de janeiro de 2006, de cooperação entre o TSE e a Receita Federal. Tal cooperação prevê o cruzamento de informações entre as duas instituições, sendo assim possível verificar o cumprimento dos limites de doações de $10 \%$ do rendimento anual para pessoas físicas e $2 \%$ do faturamento bruto do ano anterior para pessoas jurídicas ${ }^{13}$.

Nesse artigo, procuramos demonstrar que o dinheiro ("receitas" e "despesas") impacta o resultado, ou seja, os eleitos têm campanhas mais caras. Incumbents gastam mais do que não-eleitos. Verificamos variações de gastos por distrito (estado) e câmara (Câmara dos Deputados e Senado); e as variações conforme partido político. Nessa parte, as variáveis dependentes foram: a) "voto" número de votos recebido; e b) "resultado" - resultado na eleição em "eleito", "não-

\footnotetext{
10 Informações disponíveis em: <http://www.tse.gov.br/sadEleicao2006DivCand/>. Acesso em: [jun. 2009].

${ }_{11}$ Mais especificamente, editou-se a Lei $n^{\circ} 8.713$, de 30 de setembro de 1993, que estabeleceu regras para as eleições de 1994. A Lei $n^{\circ}$ 9.504, de 30 de setembro de 1997, contém as normas ora vigentes para as eleições.

12 O debate sobre os efeitos do dinheiro, nas eleições norte-americanas, é um debate sobre quanto advertising o candidato poderá comprar. A ideia consensual é de que dinheiro compra visibilidade nos meios de comunicação, e esta é causa direta e imediata dos votos.

13 Contudo, muitas interpretações da lei ainda desafiam o poder judiciário. Uma das formas mais comuns que as empresas adotam para burlar a limitação legal é criar identidades fiscais distintas (CNPJs) para cada departamento, dentro da mesma empresa, e usar o orçamento de toda a empresa como base dos $2 \%$ de cada departamento. Assim, multiplica-se a sua capacidade de influenciar 0 processo eleitoral "dentro" da lei.
} 
eleito". Utilizamos "receitas" e "despesas", intercambiavelmente, porque são colineares em $r=0,99$. Atualizamos os valores originais em reais $(R \$)$, para fins de comparabilidade, até o mês de setembro de 2009. Utilizamos o IPCA - Índice Nacional de Preços ao Consumidor Amplo -, índice oficial de inflação usado pelo Banco Central e calculado pelo IBGE - Instituto Brasileiro de Geografia e Estatística. Portanto, os valores apresentados não são os disponíveis no site do TSE, mas dados atualizados. Além disso, como dito na introdução, nosso artigo considera, para efeito de análise, apenas os candidatos à Câmara dos Deputados (CD) e ao Senado Federal (SF) que prestaram contas dos valores recebidos e gastos.

Passamos agora para a consideração dos dados, relacionando-os às perguntas propostas na introdução deste artigo

\section{Gastos importam?}

Nossa análise começa com as diferenças, em termos de recursos gastos em campanha, entre os candidatos vencedores e perdedores, para 2002 e 2006, como apresentado pelo método de análise de "Box-and-Whisker plot". A Figura 1 ilustra essas diferenças. 
Figura 1 - Gastos em campanha

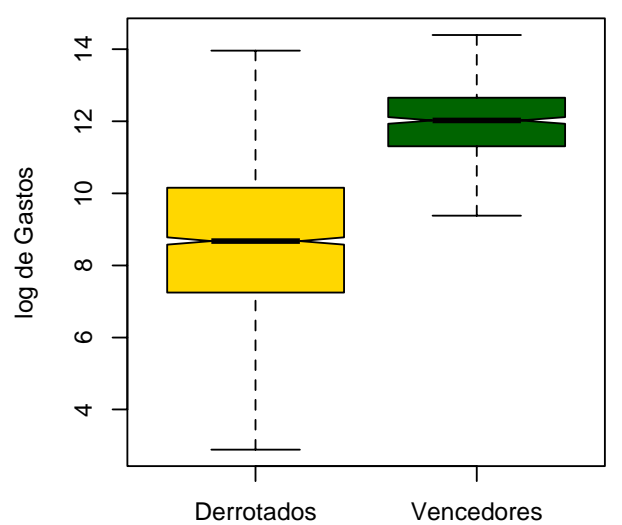

Eleição para a Câmara em 2002

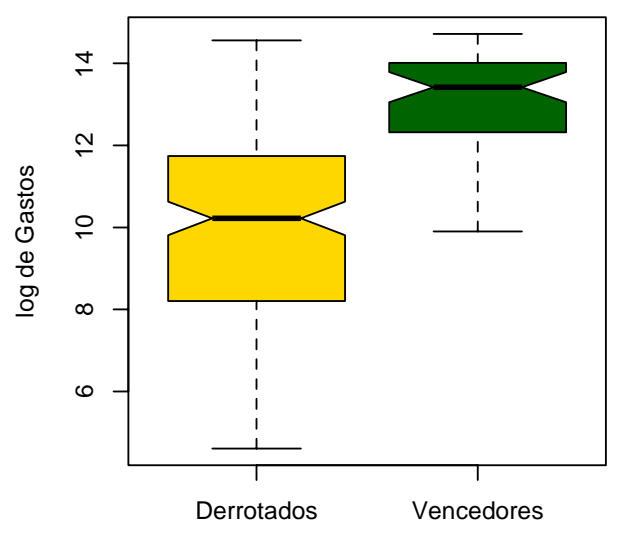

Eleição para o Senado em 2002
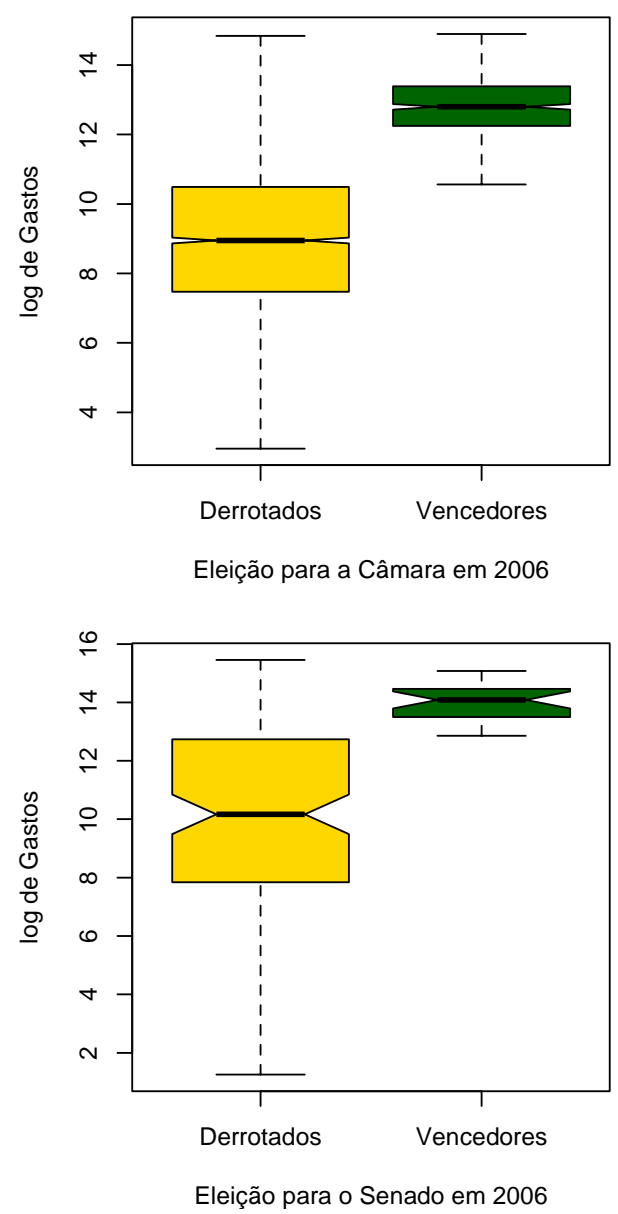

Fonte: dados do TSE - elaboração dos autores.

O que a Figura 1 nos diz a respeito do custo mínimo de uma candidatura competitiva? Usando uma escala logarítmica para a variável "gastos declarados", interpreta-se que os candidatos vencedores gastaram, em média, 5 vezes mais do que os adversários. A Figura 1 sugere, ainda, que a diferença de gastos entre quem ganha e quem perde a eleição aumentou de um pleito para outro. Ao mesmo tempo, a dispersão dos gastos na campanha entre os que vencem vem diminuindo. Entre os que perderam, no entanto, a dispersão aumentou: alguns candidatos derrotados investiram muito em suas campanhas e não foram eleitos. Ainda assim, é evidente que o caixa de campanha é um dos responsáveis pelo sucesso eleitoral.

A Tabela 1 traz os valores de maneira detalhada. Em 2002, enquanto a média de gastos dos candidatos eleitos para o Senado foi de $R \$ 1,3$ milhão, os que perderam gastaram cerca de R\$235 mil. Na Câmara, não foi diferente: os eleitos 
gastaram ao redor de $R \$ 353$ mil, os que perderam gastaram, em média, $R \$ 16$ mil e os suplentes, $\mathrm{R} \$ 66$ mil. Algo similar ocorreu nas eleições de 2006: $\mathrm{R} \$ 1,6$ milhão foi a média de gasto dos senadores vitoriosos, ao passo que os derrotados gastaram, em média, $R \$ 461$ mil. O abismo entre vencedores, perdedores e suplentes, para a Câmara dos Deputados, é ainda maior: $R \$ 589$ mil, $R \$ 11$ mil e $\mathrm{R} \$ 77$ mil respectivamente.

Tabela 1

Sumário dos gastos de eleitos e não-eleitos para CD e SF, 2002 e 2006 (R\$)

\begin{tabular}{|c|c|c|c|c|c|}
\hline Ano & Casa & Resultado & Média & Mediana & Desvio \\
\hline \multirow{5}{*}{ ָ̊ } & Senado & Derrotados & $235.308,93$ & $43.163,97$ & $505.847,33$ \\
\hline & Câmara & Derrotados & $15.868,46$ & $2.306,04$ & $76.406,87$ \\
\hline & Câmara & Suplentes & $65.611,29$ & $13.452,19$ & $169.116,46$ \\
\hline & Senado & Vencedores & $1.278 .813,67$ & $1.056 .690,29$ & $1.081 .234,47$ \\
\hline & Câmara & Vencedores & $353.346,85$ & $261.163,16$ & $323.694,85$ \\
\hline \multirow{5}{*}{$\begin{array}{l}\text { ஜ } \\
\text { ঠ }\end{array}$} & Senado & Derrotados & $460.675,01$ & $30.265,92$ & $1.000 .444,41$ \\
\hline & Câmara & Derrotados & $11.235,73$ & $2.323,72$ & $30.032,11$ \\
\hline & Câmara & Suplentes & $77.017,12$ & $13.191,66$ & $212.368,08$ \\
\hline & Senado & Vencedores & $1.623 .136,29$ & $1.523 .138,02$ & $1.069 .954,25$ \\
\hline & Câmara & Vencedores & $588.911,70$ & $421.468,35$ & $523.914,55$ \\
\hline
\end{tabular}

Fonte: Dados do TSE - elaboração dos autores.

Embora existam muitos casos extremos, nos dois sentidos das médias, podemos sustentar que as duas categorias de candidatos apresentam padrões distintos: os eleitos apresentam uma média com menor dispersão, enquanto os não-eleitos, maior dispersão. Portanto, se de um lado, o problema dos dados é a existência de uma enorme variância (limite inferior $R \$ 0,00$ e superior de $R \$ 5$ milhões) $)^{14}$; de outro, a variabilidade do montante das receitas e despesas também fornece pistas sobre a sorte dos candidatos nas urnas.

Demonstrada a importância dos gastos para o sucesso eleitoral - ao visualizarmos a comparação entre os caixas de quem ganha e quem perde -, apresentamos, na próxima seção, as diferenças de receitas e gastos entre os candidatos à reeleição e os seus desafiantes.

\footnotetext{
${ }^{14}$ Há candidatos que declaram não ter recebido receita alguma e também não ter investido um só real na campanha. Já a parcela de candidatos com gastos astronômicos é menor. O maior valor declarado foi da candidata ao Senado por Roraima, Teresa Jucá, esposa de senador pelo mesmo estado, Romero Jucá. Nesse caso, em particular, só o suplente da candidata, José João Abdalla Filho, foi responsável pela doação de mais de $\mathrm{R} \$ 5$ milhões de reais.
} 
Incumbents e Challengers

Salta aos olhos os resultados trazidos pela Tabela 2. Nela, podemos contrastar as informações de receitas e gastos declarados para os dois grupos de candidatos - os candidatos à reeleição e os desafiantes, tanto no Senado como na Câmara. Como esperado, os dados informam que os candidatos à reeleição recebem mais doações e gastam, em média, muito mais do que seus desafiantes. Ademais, o erro padrão nos indica que a dispersão em torno da média é menor entre os desafiantes do que entre os candidatos à reeleição. Isso ocorre tanto no Senado quanto na Câmara.

Tabela 2

Receitas e gastos médios: candidatos à reeleição e desafiantes $(R \$)$

\begin{tabular}{|c|c|c|c|c|}
\hline \multirow[b]{2}{*}{ Senado } & \multicolumn{2}{|c|}{ Reeleição } & \multicolumn{2}{|c|}{ Desafiantes } \\
\hline & 2002 & 2006 & 2002 & 2006 \\
\hline Receitas & $859.200,18$ & $1.735 .951,06$ & $396.607,91$ & $441.042,83$ \\
\hline Despesas & $858.886,46$ & $1.734 .299,27$ & $404.480,36$ & $441.454,44$ \\
\hline \multicolumn{5}{|l|}{ Câmara } \\
\hline Receitas & $372.595,01$ & $503.844,91$ & $65.459,31$ & $66.830,97$ \\
\hline Despesas & $372.084,49$ & $504.804,15$ & $66.704,22$ & $66.900,43$ \\
\hline
\end{tabular}

Fonte: dados do TSE - elaboração dos autores.

Mais precisamente, os challengers, em geral, têm muito menos recursos em suas campanhas. Isso foi verificado nos dois pleitos, tanto no Senado quanto na Câmara dos Deputados. Entretanto, como apontado anteriormente, há uma grande variância na média, a qual não deixa dúvidas de que devem existir outras variáveis intervenientes a serem exploradas. Uma delas diz respeito às diferentes estratégias empregadas, conforme o distrito eleitoral. Assim, a seguir, vamos tratar das variações regionais: quanto custa um parlamentar por estado?

\section{Variações regionais e camerais}

Nesta seção, analisamos as variações nos distritos eleitorais: as campanhas têm custos semelhantes nos diversos estados brasileiros? Certamente, o "peso" de cada real recebido ou gasto numa campanha não é o mesmo entre os estados. Espera-se, pois, que as profundas clivagens socioeconômicas dos distritos eleitorais afetem as contribuições e despesas realizadas.

Como visto anteriormente, os valores declarados de receitas e despesas são 
praticamente coincidentes. De forma que, nas próximas análises, utilizamos somente o indicador "gastos". Para facilitar a comparação, criamos um índice dos gastos que pudesse nos indicar, entre os números apresentados nas tabelas, quais os estados eleitoralmente "mais caros". O índice foi obtido com a seguinte fórmula:

$$
\text { IG }=\left(\frac{\$ \mu_{\text {eleitos }}+\$ \mu_{\text {não.eleitos }}}{\sum \text { eleitores }}\right) \sum \text { candidatos }
$$

Ou seja, somou-se a média dos gastos dos eleitos e não-eleitos, dividiu-se pelo quantitativo dos eleitores no distrito e multiplicou-se pelo número de candidatos no distrito. As próximas tabelas apresentam, por distrito eleitoral (estado), o número de eleitores e de candidatos e a média dos gastos de eleitos e não eleitos ao Senado Federal (Tabela 3) e à Câmara dos Deputados (Tabela 4). Em ambas as tabelas, preferimos não distinguir os gastos entre candidatos à reeleição e candidatos desafiantes, mas entre os resultados das médias de eleitos e nãoeleitos em cada estado. Esses dados estão plotados na Figura 2, que sintetiza os resultados da análise.

Conforme a Tabela 3, para o Senado, os dados mostram que, num extremo, o eleitorado do Amapá cresceu 24\%, enquanto no outro, o Rio Grande do Sul, quinto maior colégio eleitoral, ele aumentou apenas $5 \%$. Houve aumento do número de candidatos, de 2002 para 2006, apesar de haver eleicão para 2 vagas no primeiro ano e somente para 1 vaga no segundo, em Alagoas (25\%) e no Amapá (83\%). Em tese, isso sugere aumento na competição eleitoral que pode estar ligada à ruptura ou fragilização de oligarquias locais.

Pode-se ainda observar que, em 2002, as cinco campanhas mais caras, por candidato e em média, ocorreram em Minas Gerais, Ceará, Distrito Federal, Pernambuco em Alagoas, nessa ordem. Desses colégios eleitorais, somente Minas Gerais está entre os cinco maiores. Em 2006, as cinco campanhas mais caras localizaram-se em Goiás, Piauí, Espírito Santo, Minas Gerais e Tocantins, nessa ordem. Novamente, Minas Gerais é o único grande colégio eleitoral representado. Ademais, o gasto médio dos candidatos não-eleitos superou o dos eleitos, em 2002, no Amapá e em Sergipe, e, em 2006, Alagoas, Bahia, Rio Grande do Norte e Roraima. Ou seja, essa inversão de expectativas ocorreu apenas em estados localizados no norte e nordeste do país e, com exceção da Bahia, todos pequenos colégios eleitorais. 
Tabela 3

Média dos gastos por estado para o Senado Federal (R\$)

\begin{tabular}{|c|c|c|c|c|c|c|c|c|c|c|}
\hline \multirow[b]{2}{*}{ Estado } & \multicolumn{3}{|c|}{ Eleitores } & \multicolumn{3}{|c|}{ Candidatos } & \multicolumn{2}{|c|}{ Média eleitos } & \multicolumn{2}{|c|}{ Média não eleitos } \\
\hline & 2002 & 2006 & $\%$ Var & 2002 & 2006 & $\%$ Var & 2002 & 2006 & 2002 & 2006 \\
\hline$A C$ & 369.786 & 412.840 & $12 \%$ & 6 & 4 & $.33 \%$ & 257.995 & 189.458 & 177.031 & 10.001 \\
\hline$A L$ & 1.593 .685 & 1.852 .111 & $16 \%$ & 8 & 10 & $25 \%$ & 2.128 .237 & 446.937 & 35.004 & 319.717 \\
\hline AM & 1.524 .727 & 1.781 .094 & $17 \%$ & 7 & 7 & $0 \%$ & 1.388 .833 & 1.541 .696 & 79.013 & 701.499 \\
\hline AP & 290.101 & 360.614 & $24 \%$ & 6 & 11 & $83 \%$ & 62.261 & 1.971 .692 & 341.807 & 12.564 \\
\hline BA & 8.543 .820 & 9.079 .534 & $6 \%$ & 10 & 8 & $.20 \%$ & 1.182 .736 & 583.242 & 73.800 & 423.997 \\
\hline CE & 4.805 .259 & 5.361 .581 & $12 \%$ & 8 & 6 & $.25 \%$ & 2.690 .040 & 1.232 .049 & 107.744 & 456.855 \\
\hline DF & 1.518 .438 & 1.655 .050 & $9 \%$ & 15 & 9 & $.40 \%$ & 2.538 .749 & 1.873 .728 & 139.332 & 83.884 \\
\hline ES & 2.139 .186 & 2.328 .148 & $9 \%$ & 8 & 5 & $.38 \%$ & 1.211 .469 & 3.010 .518 & 331.271 & 340.089 \\
\hline GO & 3.357 .494 & 3.723 .473 & $11 \%$ & 11 & 5 & $.55 \%$ & 1.438 .910 & 4.125 .627 & 256.265 & 67.624 \\
\hline MA & 3.391 .814 & 3.920 .608 & $16 \%$ & 9 & 9 & $0 \%$ & 1.437 .623 & 94.430 & 41.692 & 83.167 \\
\hline$M G$ & 12.680 .584 & 13.679 .738 & $8 \%$ & 17 & 10 & $.41 \%$ & 3.854 .849 & 2.924 .460 & 408.809 & 742.433 \\
\hline MS & 1.411 .773 & 1.559 .406 & $10 \%$ & 7 & 7 & $0 \%$ & 1.441 .141 & 748.382 & 104.577 & 62.669 \\
\hline MT & 1.694 .068 & 1.890 .663 & $12 \%$ & 8 & 8 & $0 \%$ & 1.239 .891 & 1.230 .814 & 622.128 & 165.437 \\
\hline PA & 3.569 .333 & 4.157 .735 & $16 \%$ & 15 & 4 & $.73 \%$ & 538.944 & 1.523 .138 & 220.457 & 601.704 \\
\hline $\mathrm{PB}$ & 2.322 .068 & 2.573 .766 & $11 \%$ & 10 & 8 & $.20 \%$ & 422.252 & 843.905 & 162.596 & 351.101 \\
\hline PE & 5.396 .667 & 5.834 .512 & $8 \%$ & 12 & 8 & $.33 \%$ & 2.428 .515 & 2.457 .153 & 150.444 & 96.718 \\
\hline $\mathrm{PI}$ & 1.842 .910 & 2.060 .045 & $12 \%$ & 11 & 9 & $.18 \%$ & 1.548 .690 & 3.825 .351 & 93.481 & 316.541 \\
\hline PR & 6.663 .381 & 7.118 .397 & $7 \%$ & 17 & 10 & $.41 \%$ & 778.082 & 1.769 .956 & 239.382 & 212.109 \\
\hline RJ & 10.103 .941 & 10.769 .323 & $7 \%$ & 23 & 13 & $.43 \%$ & 1.353 .946 & 2.296 .164 & 298.842 & 659.625 \\
\hline RN & 1.895 .897 & 2.084.247 & $10 \%$ & 12 & 8 & $.33 \%$ & 1.241 .128 & 891.195 & 153.393 & 644.024 \\
\hline $\mathrm{RO}$ & 882.545 & 988.631 & $12 \%$ & 16 & 5 & $.69 \%$ & 302.773 & 1.142 .937 & 199.534 & 462.217 \\
\hline $\mathrm{RR}$ & 208.524 & 233.596 & $12 \%$ & 11 & 6 & $.45 \%$ & 360.735 & 459.344 & 52.860 & 1.499 .080 \\
\hline RS & 7.293 .063 & 7.693 .780 & $5 \%$ & 17 & 10 & $.41 \%$ & 675.319 & 844.446 & 157.019 & 198.013 \\
\hline SC & 3.815 .056 & 4.168.495 & $9 \%$ & 11 & 7 & $.36 \%$ & 603.624 & 898.932 & 591.933 & 136.133 \\
\hline SE & 1.147 .933 & 1.299 .785 & $13 \%$ & 13 & 5 & $.62 \%$ & 36.390 & 1.901 .945 & 59.904 & 327.869 \\
\hline SP & 25.655 .553 & 28.037 .734 & $9 \%$ & 27 & 19 & $.30 \%$ & 1.942 .898 & 2.134 .769 & 408.033 & 254.346 \\
\hline TO & 785.397 & 882.728 & $12 \%$ & 6 & 6 & $0 \%$ & 813.664 & 2.862 .416 & 161.643 & 672.176 \\
\hline BRASIL & 114.903 .003 & 125.507 .634 & $11 \%$ & 321 & 217 & $.26 \%$ & 1.256 .285 & 1.623 .136 & 209.926 & 366.726 \\
\hline
\end{tabular}

Fonte: dados do TSE - elaboração dos autores.

Tais resultados, portanto, indicam não haver uma relação entre tamanho do colégio eleitoral e gastos de campanha, mas apontam para a existência de outros fatores explicativos, além do tamanho do distrito e do número de candidatos, como definidor desses gastos. Para o Senado, há indicadores de que dinâmicas regionais podem contrariar as expectativas baseadas nos gastos de campanha declarados, passando por arranjos políticos, acesso privilegiado aos meios de informação e, até mesmo, dificuldades quanto à divulgação de campanha. Por exemplo, na Amazônia, o acesso a determinadas comunidades é certamente difícil. Ademais, indicadores 
de desenvolvimento socioeconômico podem influenciar nas escolhas do eleitorado e, portanto, nas estratégias dos que pleiteiam uma vaga.

Passamos agora à exposição dos gastos para se concorrer à Câmara dos Deputados, em 2002 e 2006. A Tabela 4 evidencia a redução do número de candidatos às 513 vagas da Câmara, entre 2002 e 2006, em 9 estados, ou seja, $1 / 3$ das 27 unidades federativas. Isso não ocorreu em nenhum dos 5 maiores colégios eleitorais do país. Tampouco há casos, em 2002 ou 2006, em que a média dos gastos declarados dos candidatos eleitos supere a média dos gastos dos não eleitos.

No que tange aos dispêndios com a campanha, temos que os cinco estados onde a média dos eleitos foi mais alta foram: Goiás ( $R \$ 625$ mil), Alagoas ( $R \$ 624$ mil), Distrito Federal ( $R \$ 495$ mil), Pernambuco $(R \$ 464$ mil) e, empatados em quinto, Rio de Janeiro e São Paulo (R\$ 430 mil). Vemos aqui que, nas eleições proporcionais, os grandes colégios aparecem entre os que mais gastam, embora não em primeiro lugar. Nas eleições de 2006, Goiás continuou na primeira posição, seguido de São Paulo, Paraná, Pernambuco e Espírito Santo. Nesse pleito, a média mais alta de candidato foi $R \$ 1,1$ milhão, o que representa um aumento de $55 \%$, em relação à média da eleição anterior. A partir das Tabelas 3 e 4, plotamos os gráficos representados na Figura 2, que permite uma melhor visualização da dinâmica dos gastos de campanha nos estados. 
Tabela 4

Média dos gastos por estado para a Câmara dos Deputados (R\$)

\begin{tabular}{|c|c|c|c|c|c|c|c|c|c|c|}
\hline \multirow[b]{2}{*}{ Estado } & \multicolumn{3}{|c|}{ Eleitores } & \multicolumn{3}{|c|}{ Candidatos } & \multicolumn{2}{|c|}{ Média eleitos } & \multicolumn{2}{|c|}{ Média não eleitos } \\
\hline & 2002 & 2006 & $\%$ Var & 2002 & 2006 & $\%$ Var & 2002 & 2006 & 2002 & 2006 \\
\hline$A C$ & 369.786 & 412.840 & $12 \%$ & 69 & 57 & $.17 \%$ & 94.213 & 220.735 & 34.123 & 41.180 \\
\hline$A L$ & 1.593 .685 & 1.852 .111 & $16 \%$ & 76 & 88 & $16 \%$ & 624.300 & 383.131 & 90.981 & 39.713 \\
\hline AM & 1.524 .727 & 1.781 .094 & $17 \%$ & 69 & 78 & $13 \%$ & 235.258 & 290.684 & 67.080 & 34.837 \\
\hline AP & 290.101 & 360.614 & $24 \%$ & 64 & 66 & $3 \%$ & 61.073 & 198.235 & 16.180 & 32.992 \\
\hline BA & 8.543 .820 & 9.079 .534 & $6 \%$ & 134 & 246 & $84 \%$ & 299.201 & 424.786 & 71.666 & 27.410 \\
\hline CE & 4.805 .259 & 5.361 .581 & $12 \%$ & 122 & 148 & $21 \%$ & 279.277 & 424.363 & 44.275 & 33.779 \\
\hline DF & 1.518 .438 & 1.655 .050 & $9 \%$ & 107 & 106 & $.1 \%$ & 494.930 & 436.256 & 63.647 & 112.967 \\
\hline ES & 2.139 .186 & 2.328 .148 & $9 \%$ & 102 & 84 & $.18 \%$ & 368.202 & 742.300 & 57.025 & 59.075 \\
\hline $\mathrm{GO}$ & 3.357 .494 & 3.723 .473 & $11 \%$ & 137 & 110 & $.20 \%$ & 625.864 & 1.135 .447 & 82.042 & 111.667 \\
\hline MA & 3.391 .814 & 3.920 .608 & $16 \%$ & 138 & 157 & $14 \%$ & 258.210 & 306.150 & 30.780 & 23.079 \\
\hline$M G$ & 12.680 .584 & 13.679 .738 & $8 \%$ & 433 & 530 & $22 \%$ & 348.140 & 647.662 & 42.615 & 51.820 \\
\hline MS & 1.411 .773 & 1.559 .406 & $10 \%$ & 88 & 75 & $.15 \%$ & 351.150 & 696.164 & 87.554 & 50.746 \\
\hline MT & 1.694 .068 & 1.890 .663 & $12 \%$ & 65 & 93 & $43 \%$ & 458.193 & 644.535 & 91.496 & 107.846 \\
\hline PA & 3.569 .333 & 4.157 .735 & $16 \%$ & 119 & 137 & $15 \%$ & 301.158 & 483.045 & 40.989 & 22.768 \\
\hline PB & 2.322 .068 & 2.573 .766 & $11 \%$ & 91 & 88 & $.3 \%$ & 162.072 & 289.292 & 39.068 & 28.905 \\
\hline PE & 5.396 .667 & 5.834 .512 & $8 \%$ & 191 & 210 & $10 \%$ & 464.266 & 757.623 & 96.370 & 21.666 \\
\hline $\mathrm{PI}$ & 1.842 .910 & 2.060 .045 & $12 \%$ & 80 & 86 & $8 \%$ & 300.376 & 493.843 & 30.372 & 29.418 \\
\hline PR & 6.663 .381 & 7.118 .397 & $7 \%$ & 210 & 267 & $27 \%$ & 394.871 & 858.953 & 63.226 & 54.419 \\
\hline RJ & 10.103 .941 & 10.769 .323 & $7 \%$ & 576 & 719 & $25 \%$ & 430.728 & 447.740 & 63.647 & 27.963 \\
\hline RN & 1.895 .897 & 2.084 .247 & $10 \%$ & 75 & 70 & $.7 \%$ & 305.230 & 512.658 & 22.804 & 26.930 \\
\hline $\mathrm{RO}$ & 882.545 & 988.631 & $12 \%$ & 106 & 74 & $.30 \%$ & 204.241 & 239.984 & 49.151 & 52.519 \\
\hline RR & 208.524 & 233.596 & $12 \%$ & 71 & 83 & $17 \%$ & 155.918 & 184.378 & 27.763 & 21.177 \\
\hline RS & 7.293 .063 & 7.693 .780 & $5 \%$ & 202 & 280 & $39 \%$ & 341.495 & 452.505 & 49.807 & 41.915 \\
\hline SC & 3.815 .056 & 4.168 .495 & $9 \%$ & 124 & 131 & $6 \%$ & 285.314 & 591.790 & 55.646 & 68.083 \\
\hline SE & 1.147 .933 & 1.299 .785 & $13 \%$ & 73 & 52 & $.29 \%$ & 124.292 & 371.427 & 18.850 & 34.372 \\
\hline SP & 25.655 .553 & 28.037 .734 & $9 \%$ & 727 & 1059 & $46 \%$ & 430.371 & 957.670 & 58.047 & 68.914 \\
\hline TO & 785.397 & 882.728 & $12 \%$ & 61 & 75 & $23 \%$ & 250.444 & 422.343 & 32.012 & 49.185 \\
\hline BRASIL & 114.903 .003 & 125.507 .634 & $11 \%$ & 321 & 217 & $11 \%$ & 320.325 & 504.211 & 52.860 & 47.235 \\
\hline
\end{tabular}

Fonte: Dados do TSE - elaboração dos autores 
Figura 2

Índice de gastos de campanha para a Câmara (2002 e 2006)
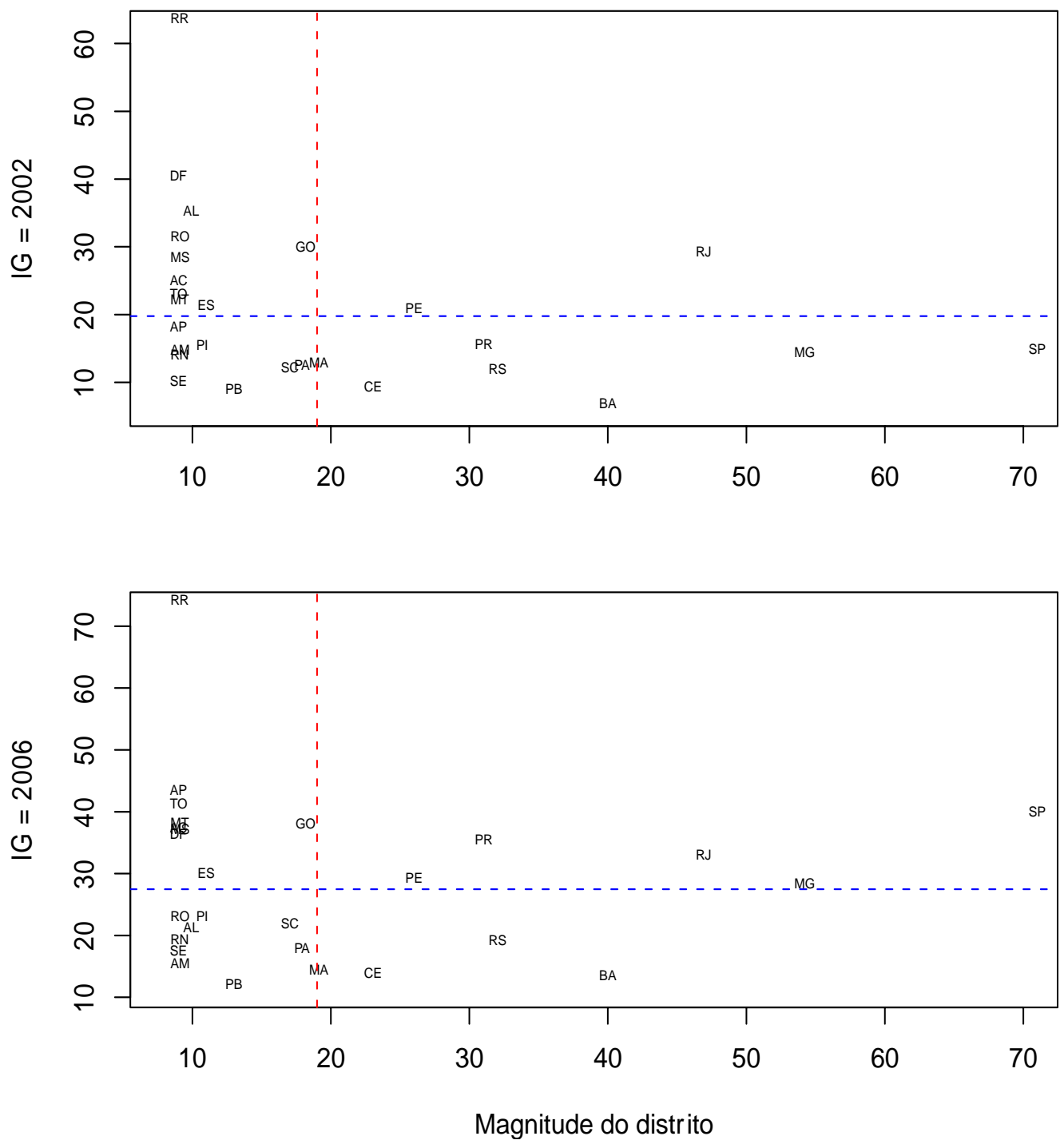

Fonte: dados do TSE - elaboração dos autores.

O primeiro quadrante de cada gráfico representa os estados com menor número de assentos na Câmara e alto índice de gastos; o segundo quadrante traz os estados com maior número de assentos e com alto índice de gastos; no terceiro quadrante, estados com menor número de assentos e com menor índice gastos; por fim, no quarto quadrante, os estados com maior número de assentos e menor 
índice de gastos. Veja que a situação, entre 2002 e 2006, muda significativamente para alguns estados, como São Paulo, que tem sua campanha bastante encarecida, mas permanece muito estável para BA, RJ, RS, CE, RR, ES, PB. A dinâmica temporal parece afetar mais alguns distritos eleitorais do que outros. Os menos afetados aparentam maior estabilidade nas suas configurações políticas relacionadas ao financiamento das campanhas.

O que a Figura 2 nos mostra? Ela nos sugere haver uma relação inversa entre distritos eleitorais menores - menor quantidade de eleitores, menor magnitude - e gastos de campanha. Embora esse argumento não possa ser usado como regra para todos os estados que aparecem no primeiro quadrante, parece claro que em estados com menor densidade demográfica, os candidatos ha maior gasto de recursos nas campanhas. Uma hipótese para estados com maior densidade populacional apresentarem custos menores pode ser dada pela concentração de eleitores, que facilitaria o uso de comunicação de massas. Outro fator poderia ser o grau de desenvolvimento socioeconomico, uma vez que a maior parte dos estados no primeiro quadrante apresentam baixo IDH. Entretanto, como nesse artigo não estamos explorando tais variáveis, mas apenas traçando um panorama geral, fica a pergunta, a ser explorada em estudos posteriores. Um ultimo dado: corroborando o argumento de Samuels (2006), as campanhas têm-se tornado, na média, mais "caras" na Câmara. Ainda que alguns estados não apresentem alteração de posição relativa nos quadrantes acima, fica fácil constatar a evolução geral dos índices padronizados, olhando-se para o deslocamento ocorrido, ao longo do eixo "y", no valor de corte do eixo "x". Ademais, a passagem de alguns dos grandes estados do quarto para o terceiro quadrante afetou, significativamente, o ajuste da média em 2006.

No Senado, como o número de assentos no é igual para todos os estados, o índice pode ser representado num gráfico de barras. Na Figura 3, a seguir, chama atenção o aumento brutal no valor das campanhas nos estados do Amapá e Roraima entre as duas eleições - o que explicaria tal fato? Competição acirrada? Subprestação de contas no ano de 2002 e ajuste no ano de 2006? Com o tipo de dados que estamos lidando nada podemos afirmar; mas acenam para maior investigação sobre a variância do financiamento de campanhas no território nacional, e estudos de caso podem trazer a tona mais informações sobre o processo eleitoral. 
Figura 3

Índice de gastos de campanha para o Senado (2002 e 2006)

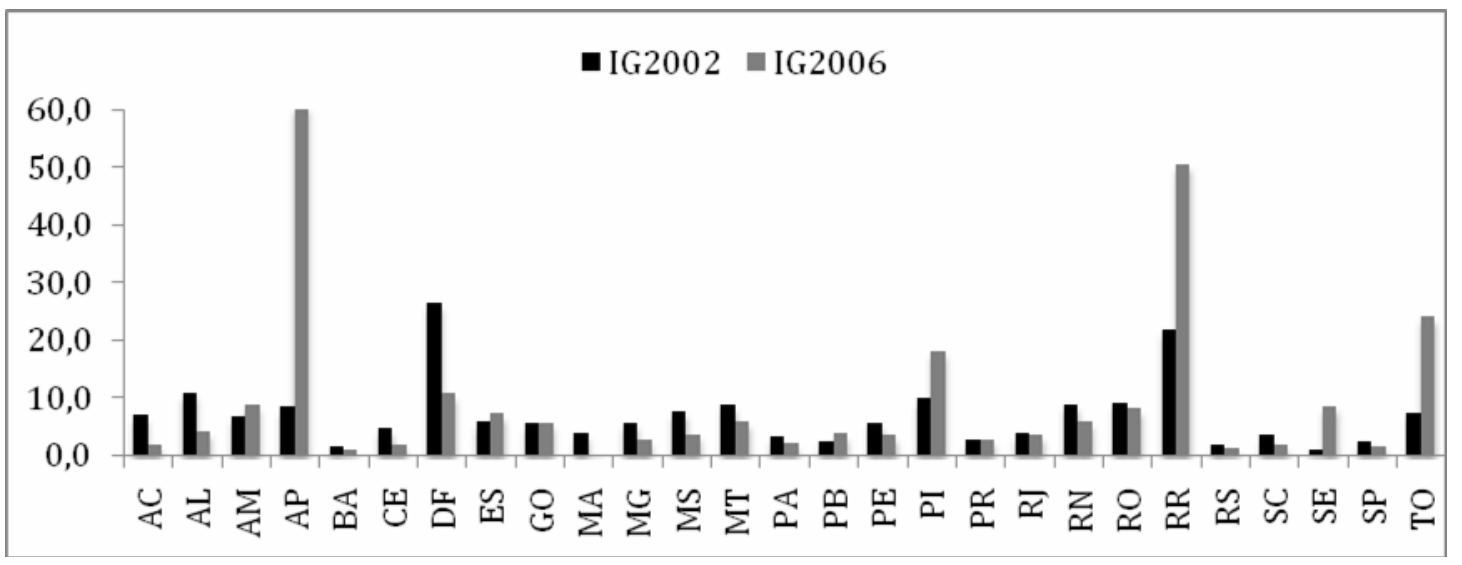

Fonte: dados do TSE - elaboração dos autores.

Considerando as variações dadas pelas incongruências do bicameralismo brasileiro (LIJPHART, 1984), com acessos a diferentes recursos e incentivos distintos para os candidatos a uma e a outra Casa, seria razoável que houvesse discrepâncias nos gastos desses candidatos. Poder-se-ia esperar um gasto maior na Câmara, uma vez que a literatura aponta para campanhas proporcionais extremamente competitivas, tanto dentro do partido quanto fora dele, e com grande incerteza. Entretanto, o que observamos é um gasto três vezes maior no Senado em 2002, e seis vezes maior em 2006. Ademais, quando resolvemos olhar para a diferença entre os candidatos reconduzidos e os candidatos desafiantes eleitos, na Tabela 5, os resultados revelam um quadro contraditório entre as duas Casas do Congresso brasileiro.

O desvio-padrão dos valores apresentados na Tabela 5 distingue as médias dos dois grupos. Em 2002, entre os senadores incumbents o desvio foi de $\mathrm{R} \$ 866$ mil, em ambas as médias (receitas e despesas). Para os challengers, o desvio foi de $\mathrm{R} \$ 1,2$ milhão. Em 2006, a média dos senadores incumbents tem desvio-padrão de $\mathrm{R} \$ 803$ mil, para as despesas, e $\mathrm{R} \$ 805$ mil, para as receitas. Entre os senadores desafiantes, o valor foi mais uma vez maior: $R \$ 1,1$ milhão e $R \$ 1,2$ milhão, respectivamente, nas despesas e receitas. Para a Câmara, o desvio foi de $R \$ 327$ mil, nos deputados incumbents, e R $\$ 309$ mil entre os challengers, em 2002; em 2006, os valores dos desvios entre os incumbents são de $\mathrm{R} \$ 498$ mil para as despesas e receitas. Entre os challengers, o desvio foi de $R \$ 550$ mil e $R \$ 552$ mil, respectivamente, nas despesas e receitas. 
Tabela 5

Média dos gastos entre os candidatos eleitos (R\$)

\begin{tabular}{|l|c|c|c|c|c|c|}
\hline & \multicolumn{2}{|c|}{ Incumbents Eleitos } & Diferença & \multicolumn{2}{c|}{ Challengers Eleitos } & Diferença \\
\hline Senado & $\mathbf{2 0 0 2}$ & $\mathbf{2 0 0 6}$ & $\mathbf{2 0 0 2}$ & $\mathbf{2 0 0 2}$ & $\mathbf{2 0 0 6}$ & $\mathbf{2 0 0 6}$ \\
\hline Receitas & 1.199 .845 & 1.325 .910 & -110.976 & 1.310 .822 & 1.739 .236 & .413 .327 \\
\hline Despesas & 1.199 .443 & 1.324 .516 & -110.701 & 1.310 .144 & 1.727 .654 & .403 .138 \\
\hline Câmara \\
\hline Receitas & 397.127 & 626.691 & 106.029 & 291.098 & 546.475 & 80.216 \\
\hline Despesas & 397.076 & 626.293 & 106.110 & 290.966 & 545.039 & 81.254 \\
\hline
\end{tabular}

Fonte: Dados do TSE elaboração dos autores

Segundo as informações da Tabela 5, os gastos apresentados pelos incumbents e challengers à Câmara dos Deputados seguem os argumentos de Jacobson (1980; 1987) para o Congresso norte-americano. Ou seja, os incumbents gastam mais e têm mais dinheiro à disposição dos que os challengers, contudo, os últimos conseguem resultados semelhantes (vencer eleições) investindo proporcionalmente menos dinheiro ${ }^{15}$. Os candidatos desafiantes gastam menos porque têm menos acesso, em geral, aos recursos escassos. Já no Senado o quadro é distinto: os challengers eleitos para a Câmara Alta gastaram somas adicionais se comparados aos gastos dos incumbents nos dois períodos. Os desafiantes ao Senado conseguiram mais doações para suas campanhas, o que pode indicar um certo descontentamento com a atuação ou representação do incumbent nos anos anteriores, por um lado; ou, por outro, pode indicar que os senadores incumbents conseguem aferir maiores vantagens enquanto estão nos cargos, precluindo de certa forma do financiamento eleitoral.

Embora a teoria aponte que a obtenção de fundos para a campanha é responsabilidade dos candidatos e não dos partidos, é possível que haja determinadas padrões no financiamento de campanhas entre os partidos brasileiros, a próxima seção tratará dessa análise.

\footnotetext{
15 Esses resultados devem ser mais bem explorados, já que os podem estar enviesados pelas características do sistema proporcional de lista aberta adotado no Brasil. Portando, no que concerne à Câmara, preferimos dizer que são dados provisórios, já que não identificamos a forma de entrada dos challengers e incumbents: se foram eleitos com votos próprios ou pela média.
} 
Variações partidárias

O nosso interesse aqui consiste em verificar se existem variações partidárias: há campanhas mais "caras" ou mais "baratas", segundo a origem partidária dos candidatos? Examinamos aqui as variações das despesas de campanha dos cinco principais partidos brasileiros com representação no Congresso - PT, PMDB, PSDB, PDT e DEM. Esses partidos distribuem-se por toda a gama do espectro ideológico. Dentre eles, o PT é o partido percebido como mais à esquerda; seguem PSDB e PMDB, ao centro; e DEM, já mais próximo à direita. $O$ PDT situa-se entre o PSDB e o PT. Tal configuração manteve-se estável nos últimos vinte anos, apesar das mudanças sociais e econômicas significativas das duas últimas décadas (POWER e ZUCCO, 2009, p.239) ${ }^{16}$.

Segundo a lógica da conexão eleitoral (MAYHEW, 2004), poder-se-ia dizer que as diferenças partidárias pouco afetariam os gastos de campanha: a busca pelo financiamento e a natureza dos gastos, dados os incentivos para a competição e a racionalidade do sistema, teriam a mesma natureza em todos os partidos do espectro ideológico. Ainda que os partidos possam ter posições, preferências, e mesmo ações distintas, a lógica eleitoral funcionaria igualmente para todos. Além disso, como o voto no Brasil é considerado um dos mais personalizados do mundo (CAREY e SHUGART, 1995), o impacto da sigla partidária sobre as campanhas seriam basicamente os mesmos - muito baixos.

De outro lado, dadas algumas características do sistema brasileiro presidencialismo de coalizão combinado com um forte poder executivo, que concentra prerogativas importantes quanto à elaboração e execução orçamentárias (SANTOS, 2003; PEREIRA e MUELLER, 2003) - criam-se incentivos para que os financiadores, ao buscar maximizar o acesso político ou realizar determinadas preferências políticas, concentrem recursos nos candidatos da base governista. Assim, espera-se que partidos da coalizão, por terem mais acesso aos instrumentos e às instituições que permitem a alocação de recursos no governo federal, sejam mais atraentes. Partidos de oposição seriam menos atraentes para os financiadores de campanha, por terem acesso limitado aos canais decisórios que permitiriam aos financiadores maximizar suas preferências. Certamente outros fatores podem afetar as doações, como as chances de vitória dos candidatos. Mas essa questão não será tratada aqui: trataremos apenas dos valores médios dos gastos dos candidatos nas duas eleições, segundo os partidos. As duas eleições são particularmente significativas para a comparação, porque representam coalizões diferentes. A primeira, de 2002, tem na sua coalizão os partidos PSDB, DEM, PMDB, dentre

\footnotetext{
${ }^{16}$ Essa distribuição é questionada na literatura, que assinala ser o sistema partidário brasileiro marcado pela incoerência e fragmentação (AMES, 1995; MAINWARING, 1999).
} 
outros; enquanto a segunda contempla PT, PMDB e PDT, entre outros.

As Tabelas 6 e 7 trazem dados interessantes. No quesito temporal, reiterase o que já notamos nesse estudo: o aumento exponencial dos gastos de campanha de 2002 para 2006. Todos os partidos, sem exceção, realizaram campanhas mais caras. O PDT, apesar de em valores absolutos ter-se mantido como o partido com as campanhas menos dispendiosas, teve um incremento de receitas/ gastos, para o Senado, em quatro vezes; o PT aumentou em 3,5 vezes; o PMDB e o DEM aumentaram praticamente 3 vezes; e o PSDB, 2,5 vezes. A ordem crescente dos gastos em termos absolutos, em 2002, foi PDT < PT < PMDB < PSDB < DEM. Ou seja, os partidos da coalizão receberam mais recursos e gastaram mais do que os partidos da oposição. Veja-se, entretanto, que não foi o PSDB - partido do presidente - o que mais amealhou recursos. Igual importância tiveram os dois principais partidos da base governista, que se constituem nas maiores bancadas das duas casas do Congresso e participam do governo com um número considerável de ministérios (AMORIM NETO, 2007). Já em 2006, a ordem crescente dos gastos para o Senado foi PDT $<$ PT $<$ PSDB $<$ DEM $<$ PMDB. Nessa caso, o $\mathrm{PMDB}$, principal aliado do governo pela sua representação no Congresso, recebeu o maior volume de recursos; e os outros dois partidos da base (PT-PDT) continuaram a receber menos do que a oposição (PSDB-DEM), embora o incremento das receitas tenha sido, como se notou anteriormente, bastante significativo.

Na campanha para a Câmara, o PT praticamente quintuplicou seus gastos, de 2002 para 2006; o PMDB quadruplicou; e o PDT, PSDB e DEM praticamente dobraram seus gastos totais, embora o ordenamento dos valores absolutos tenha-se mantido basicamente como o da campanha para o Senado: apesar do incremento que resultou na diminuição da distância entre os gastos médios declarados pelos concorrentes dos diferentes partidos, PT e PDT continuaram a receber menos recursos do que PSDB-PMDB-DEM.

Como os dados dialogam com os argumentos teóricos apresentados? Em primeiro lugar, em relação à conexão eleitoral, apesar dos incentivos serem os mesmos para os candidatos, e independentemente dos partidos eles buscarem recursos que permitam a maximização do seu interesse, a lógica dos financiadores é distinta e seletiva. Os candidatos não são todos iguais e, portanto, o financiamento não é igualmente distribuído. Entretanto, o que é mais significativo: ser parte do governo ou ser de um determinado partido político? Segundo os indicadores aqui colocados, é de fato relevante ter acesso político privilegiado - e isso pode ser interpretado pelo aumento exponencial de recursos para o PT e PDT de uma eleição para outra, quando ambos eram partidos da base, e mais ainda pelo aporte massivo de recursos ao PMDB, que fez parte da coalizão dos dois períodos e, talvez em vista disso, represente não só uma visão mais ao centro, mas a estabilidade do acesso aos canais privilegiados de interlocução. De outro lado, é 
inegável que apesar do corte governo-oposição ter algum impacto, mesmo na oposição o PSDB e DEM continuam sendo os principais recipientes de financiamento. Isso leva a crer que o fato mais importante para o doador é a homogeneidade de preferências com relação a um leque de políticas. Assim, "investir" na oposição é maximizar as próprias preferências e, ao fortalecê-las numericamente no Congresso, permitir que se contraponham às preferências do governo e possam atuar como ponto de veto. Assim, garante-se a construção de uma agenda política que demandará negociações e compromisso entre diferentes visões. Entretanto, cabe dizer que com apenas duas eleições, não podemos ir muito além nos argumentos.

\section{Tabela 6}

Média e desvio-padrão (Sd) de gastos por partido - 2002 (R\$)

\begin{tabular}{|c|l|c|c|c|r|}
\hline Partido & & Senado & Câmara & Total & $\begin{array}{r}\text { \% } \\
\text { CD/SF }\end{array}$ \\
\hline \multirow{4}{*}{ PT } & Média & 416.204 & 82.885 & 20.452 & $20 \%$ \\
\cline { 2 - 6 } & Sd & 554.688 & 138.100 & 40.922 & $25 \%$ \\
\cline { 2 - 6 } & $\mathrm{N}$ & 25 & 365 & 390 & \\
\hline \multirow{4}{*}{ PMDB } & Média & 856.615 & 188.610 & 50.094 & $22 \%$ \\
\cline { 2 - 6 } & $\mathrm{Sd}$ & 960.653 & 226.798 & 81.856 & $24 \%$ \\
\cline { 2 - 6 } & $\mathrm{N}$ & 25 & 288 & 253 & \\
\hline \multirow{3}{*}{ PSDB } & Média & 1.218 .750 & 272.456 & 69.788 & $22 \%$ \\
\cline { 2 - 6 } & Sd & 1.215 .233 & 439.243 & 119.750 & $36 \%$ \\
\cline { 2 - 6 } & $\mathrm{N}$ & 22 & 228 & 250 & \\
\hline \multirow{3}{*}{ DEM/P } & Média & 1.368 .457 & 286.253 & 80.696 & $21 \%$ \\
\cline { 2 - 6 } & $\mathrm{Sd}$ & 1.134 .628 & 305.090 & 115.336 & $27 \%$ \\
\cline { 2 - 6 } & $\mathrm{N}$ & 23 & 176 & 199 & \\
\hline \multirow{3}{*}{ PDT } & Média & 456.553 & 70.010 & 16.744 & $15 \%$ \\
\cline { 2 - 6 } & $\mathrm{Sd}$ & 549.910 & 136.749 & 34.910 & $25 \%$ \\
\cline { 2 - 6 } & $\mathrm{N}$ & 17 & 192 & 209 & \\
\hline
\end{tabular}

Fonte - Dados do TSE - elaboração dos autores 
Tabela 7

Média e desvio-padrão (Sd) de gastos por partido - 2006 (R\$)

\begin{tabular}{|c|l|c|c|c|r|}
\hline \multirow{4}{*}{ Partido } & & Senado & Câmara & Total & $\begin{array}{c}\% \\
\text { CD/SF }\end{array}$ \\
\hline \multirow{4}{*}{ PT } & Média & 686.010 & 199.928 & 91.315 & $29 \%$ \\
\cline { 2 - 6 } & Sd & 736.224 & 341.811 & 149.047 & $46 \%$ \\
\cline { 2 - 6 } & $\mathrm{N}$ & 10 & 313 & 321 & \\
\hline \multirow{4}{*}{ PMDB } & Média & 1.542 .484 & 255.483 & 133.244 & $17 \%$ \\
\cline { 2 - 6 } & Sd & 1.465 .730 & 418.026 & 224.980 & $29 \%$ \\
\cline { 2 - 6 } & $\mathrm{N}$ & 12 & 288 & 300 & \\
\hline \multirow{3}{*}{$\begin{array}{c}\text { PSDB } \\
\text { FEM }\end{array}$} & Média & 1.517 .529 & 291.022 & 148.578 & $19 \%$ \\
\cline { 2 - 6 } & Sd & 1.424 .068 & 527.866 & 262.856 & $37 \%$ \\
\cline { 2 - 6 } & $\mathrm{N}$ & 13 & 252 & 272 & \\
\cline { 2 - 6 } & Sédia & 1.511 .245 & 294.526 & 168.635 & $19 \%$ \\
\cline { 2 - 6 } & $\mathrm{N}$ & 1.091 .495 & 416.978 & 234.948 & $38 \%$ \\
\hline \multirow{3}{*}{ PDT } & Média & 456.553 & 57.515 & 35.033 & $13 \%$ \\
\cline { 2 - 6 } & Sd & 549.910 & 232.428 & 114.102 & $42 \%$ \\
\cline { 2 - 6 } & $\mathrm{N}$ & 13 & 291 & 304 & \\
\hline
\end{tabular}

Fonte - Dados do TSE - elaboração dos autores

\section{Conclusões}

O objetivo deste artigo foi explicitar a distribuição dos gastos de campanha para a Câmara e o Senado brasileiros nas eleições de 2002 e 2006, segundo a posição do candidato (se mandatário ou novato), estado da federação, câmara e partido político. A primeira conclusão a que podemos chegar é que dinheiro importa para as campanhas: os eleitos gastam, em média, cinco vezes mais do que os nãoeleitos. Podemos também indicar o encarecimento significativo da campanha de 2006, em relação à de 2002, bem como para o aumento de sua competitividade, com mais eleitores e mais candidatos. Também constatamos que a dispersão nos valores entre os candidatos vencedores é bem menor do que a dispersão entre os perdedores.

Sobre a importância da incumbency para explicar não somente o sucesso de arrecadação como o sucesso eleitoral (JACOBSON, 1980; JACOBSON e CLAWSON, 2001; STRATMAN, 2005), os resultados para o caso brasileiro confirmam o fato de que os candidatos à reeleição recebem mais recursos do que os novatos. No quadro 
geral, os primeiros gastam, em média, muito mais do que seus concorrentes: no Senado, duas vezes mais em 2002, e quase quatro vezes mais em 2006; na Câmara, cerca de 6 vezes mais em 2002, e nove vezes mais em 2006.

Outro ponto diz respeito às variações regionais no financiamento de campanha. Os maiores colégios eleitorais não apresentaram os maiores gastos médios de campanha. $\mathrm{O}$ uso das médias permitiu averiguarmos particularidades, como estados do Norte e do Nordeste em que ocorreram casos de gastos de nãoeleitos superarem, em muito, os dos eleitos, exceção que aconteceu apenas em alguns estados dessas regiões e somente para as eleições ao Senado: o gasto médio dos candidatos não-eleitos superou o dos eleitos, em 2002, no Amapá e em Sergipe, e, em 2006, Alagoas, Bahia, Rio Grande do Norte e Roraima.

No quesito das variações camerais, esperava-se comportamento também distinto dos gastos. Além do fato acima - de que alguns desafiantes nas regiões Norte e Nordeste, para o Senado, gastaram em alguns casos mais do que os "incumbents" -, notou-se um aumento do número de contribuições de 2002 para 2006, em ambas as Casas, assim como a sensível diferença no seu valor médio, entre as Casas. Foi surpreendente encontrar gasto maior no Senado e não na Câmara, uma vez que a literatura aponta que as campanhas proporcionais são extremamente competitivas. Entretanto, como os senadores fazem campanha em todo o - e não em determinados nichos onde se concentram parte dos eleitores isso acaba encarecendo bastante a campanha.

Quanto aos partidos políticos, uma evidência apontada pelos dados é que, dos cinco partidos examinados (PT, PDT, PSDB, PMDB e DEM/PFL), os candidatos dos três últimos compartilharam patamares de gastos bem mais altos do que os do PT e do PDT, ao mesmo tempo em que esses dois lideraram o aumento proporcional de gastos nas eleições de 2006, quando passaram ao governo. Viu-se que a posição governo-oposição importa, mas ainda mais relevante é a diferenciação entre os partidos políticos - o PMDB, PSDB e DEM continuam sendo, apesar da mudança de governo e da inversão de papéis, quando passaram a oposição, os principais recipientes de financiamento.

Tal evidência pode indicar tanto proximidade de preferências entre doadores-recipientes, quanto aquisição de acesso ("voz") no Congresso em relação a mudanças políticas, especialmente as de cunho mais extremado - ou mais distante das preferências dos doadores. Entretanto, tal afirmação escapa aos dados aqui apresentados. Para tanto, outra pesquisa deveria ser desenvolvida, para tratar das motivações dos doadores em relação às contribuições eleitorais. A resposta pode passar por preferências ideológicas (WELCH, 1975), mas também pela hipótese talvez mais debatida na literatura, que se refere ao ganho de acesso político às decisões coletivas via "networks of obligations" entre candidatos e doadores (CLAWSON; et al, 1998; NEUSTADTL, 1990). Esse debate leva, em última 
instância, à natureza das decisões e possíveis viéses em favor de grupos ou indivíduos que tenham contribuído para as campanhas eleitorais, os quais, por serem em pequeno número, teriam um peso desproporcional nas decisões (FRANCIA et al, 2003; SKOCPOL, 2004) ${ }^{17}$. Essa é uma avenida de futuros e promissores estudos no Brasil.

Esse debate leva ainda a outro, mais normativo, sobre qual a melhor forma de financiamento de campanha. Os sucessivos escândalos no Brasil envolvendo financiamento ilegal (contas confidenciais ou entradas encobertas: o famoso "caixa dois"), corrupção, tráfico de influências e envolvimento do crime organizado, entre outras atividades ilícitas, reforçam as críticas ao modelo de financiamento privado. Entretanto, se esse está sujeito à incidência perversa de interesses particulares, o financiamento exclusivamente público está sujeito à não menos perversa "estatização, burocratização e ossificação dos partidos (isto é, sua dependência econômica crônica dos recursos estatais e a conseguinte perda de contato com a sociedade)", como ocorreu no México (ZOVATTO, 2005, p.302). Além disso, alguns dos problemas do financiamento privado - como a menor pluralidade de partidos, devido aos privilégios de determinados grupos - podem também ocorrer dentro de um sistema exclusivamente público. Não é à toa que o International Institute for Democracy and Electoral Assistance (International IDEA) aponta o financiamento misto como modelo ideal, com ampla publicização, transparência, existência de órgãos de controle independentes e regimes eficazes de sanção, pari passu a manutenção da autonomia dos partidos (IDEA, 2003) ${ }^{18}$. Estudos comparativos entre sistemas que funcionam segundo diferentes institucionalidades podem fornecer evidências clarificadoras sobre os pontos fortes e fracos de cada sistema e, assim, auxiliar os debates sobre futuras reformas políticas sobre o tema.

Quanto a outros estudos, além das possibilidades assinaladas ao longo do texto, seria intereessante verificar as diferentes estratégias de financiamento e de gasto (onde se gasta e em quê), uma vez que os dados aqui agregados não permitem nenhuma generalização a respeito da qualidade do gasto, senão somente da quantidade. Também seria importante acompanhar a evolução dos gastos ao longo do tempo. Num sistema tão competitivo e dinâmico quanto o brasileiro, em que, nos últimos vinte anos, partidos cresceram e se consolidaram, certamente

\footnotetext{
17 Outros estudos tratam também dos vínculos que se materializam em dinheiro e apoio (endorsement) no período eleitoral (SAMUELS, 2001a; MANCUSO, 2007).

${ }^{18}$ O Brasil adota um sistema de financiamento misto de campanhas: parte dos recursos envolvidos nas eleições vem do setor público e parte de doações privadas. Os recursos públicos são recebidos de duas formas: a primeira é via fundo partidário. Os recursos do fundo, que existe desde 1965, e agrega recursos orçamentários e multas, são transferidos diretamente aos partidos e têm sido fundamentais para viabilizar a sua estrutura. A segunda forma, indireta, é via horário partidário e eleitoral gratuito, pago pela União, por intermédio de renúncias fiscais, bem como cessão de logradouros públicos etc. As contribuições privadas não podem superar $10 \%$ da renda anual das pessoas físicas ou $2 \%$ do faturamento bruto das pessoas jurídicas.
} 
valeria a pena indagar-se sobre se gastos de campanha espelham diferentes estratégias eleitorais.

\section{Referências Bibliográficas}

AMES, B. Os entraves da democracia no Brasil. Rio de Janeiro: FGV, 2003.

"Electoral Strategy under Open-List Proportional Representation". American Journal of Political Science, vol. 39, n² 2, p.406-433, 1995.

ANSOLABEHERE, S; J. M. FIGUEIREDO, et al. "Why is There so Little Money in U.S. Politics?" The Journal of Economic Perspectives, vol.17, n 1, p.105-13, $2003 .$.

BARON, D. P. "Electoral competition with informed and uninformed voters." The American Political Science Review, vol. 87, p.34-47, 1994.

BRAGA, M. do S. S.; BOURDOUKAN, A. Y. "Political parties in Brazil: party organization, electoral competition and public financing". Perspectivas, São Paulo, vol.35, p.117-148, jan./jun, 2009.

CAREY, J; SHUGART, M. "Incentives to Cultivate a Personal Vote: a Rank Ordering of Electoral Formulas". Electoral Studies, vol.14, n4, p.417-439, 1995.

CLAWSON, D. "Politics is money." Actes de la Recherche en Sciences Sociales, vol. $138, \mathrm{n}^{\circ} 1$, p.34-46, 2001.

CLAWSON, D. et al. Dollars and Votes: How business campaign contributions subvert democracy. Philadelphia: Temple University Press, 1998.

CONGRESSO EM FOCO. Haverá renovação no Congresso? 7 jul. 2009. Disponível em: $<$ http://congressoemfoco.ig.com.br/noticia.asp?cod_canal=14\&cod_publicacao=28 803>. Acesso em: [19 set. 2009].

FENNO, R. F. J. Home Style: House Members in Their Districts. New York: Longman, 2002.

FRANCIA, P. L. et al. The Financiers of Congressional Elections: investors, ideologies, and intimates. New York: Columbia University Press, 2003.

JACOBSON, G. C. "The effects of campaign spending in congressional elections." American Political Science Review, vol. 26, p.393.415, 1978. 
. Money in Congressional Elections. New Haven: Yale University Press, 1980.

'Incumbents' Advantages in the 1978 U.S. Congressional

Elections." Legislative Studies Quarterly, vol.VI, n² p.183-1999. 1981.

The Politics of Congressional Elections. Glenview: Scott, Foresman and Company, 1987.

"The effect of campaign spending in House elections: New evidence for old arguments." American Political Science Review, vol.90, p.363-372, 1990.

. Measuring Campaign Spending Effects in U.S. House Elections. In: BRADY, H. E and JOHNSTON, R. (ed.). Capturing CUSampaign Effects. Ann Arbor: University of Michigan Press, 2006.

LANGBEIN, L. I. "Money and Access: Some Empirical Evidence." The Journal of Politics vol. 48, n4, p.1052-1062, 1986.

MAINWARING, S. P. Rethinking party Systems in the Third Wave of Democratization: the case of Brazil. Stanford: Stanford University Press, 1999.

MANCUSO, W. P. O Lobby da Indústria no Congresso Nacional: Empresariado e Política no Brasil Contemporâneo. São Paulo: Humanitas/Edusp, 2007.

MAYHEW, D. R. Congress: The Electoral Connection. 2nd Ed.New Haven and London: Yale University Press, 2004.

NAVARRO, P. The Policy Game: how special interests and ideologies are stealing America. New York: John Wiley \& Sons, Ltda, 1984.

NEUSTADTL, A. "Interest-Group PACsnabship: An analysis of campaign contributions, issue visibility, and legislative impact." Social Forces, vol. $69, n^{\circ} 2$, p.549-564, 1990.

PEREIRA, C. e MUELLER, B. "Partidos fracos na arena eleitoral e partidos fortes na arena legislativa: a conexão eleitoral no Brasil." Dados, vol. 46, n4, p.735.771, 2003.

PEREIRA, C.; RENNÓ, L. R. "O que é que o reeleito tem? Dinâmicas PolíticoInstitucionais Locais e Nacionais nas Eleições de 1998 para a Câmara dos Deputados." Dados, vol.44, n², Rio de Janeiro, 2001.

. "O que é que o reeleito tem? O retorno: o esboço de uma teoria da reeleição no Brasil." Revista de Economia Política, vol.27, n4 (108), p.664-683, 2007.

SAMUELS, D. J. "Ambition and Competition: Explaining Legislative Turnover in 
Brazil". Legislative Studies Quarterly. vol.25, n³, p.481-497, 2000.

"Incumbents and Challengers on a Level Playing Field: Assessing the Impact of Campaign Finance in Brazil." The Journal of Politics, vol.63, n², p.569-584. $2001 a$.

"Money, Elections, and Democracy in Brazil. Latin American Politics and Society." vol.43, $\mathrm{n}^{\circ} 2$, p.27.48, $2001 \mathrm{~b}$.

"Does Money Matter? Credible Commitments and Campaign Finance in New Democracies: Theory and Evidence from Brazil." Comparative Politics, vol.34, ${ }^{\circ} 1$, p.23.42, 2001c.

Financiamento de Campanhas e Propostas de Reforma. In: RENNÓ, L. R. e SOARES, G. A. D. (ed.). Reforma Política: Lições da História Recente. Rio de Janeiro: Editora FGV, 2006.

SANTOS, F. O poder legislativo no presidencialismo de coalizão. Belo Horizonte: UFMG, 2003.

SKOCPOL, T. "American Democracy in an Age of Rising Inequality." Perspectives on Politics,. vol.2 p.651-666, dec. 2004.

STRATMANN, T. "The Effectiveness of Money in Ballot Measure Campaigns." Southern California Law Review, vol.78, p.102-124, 2005.

SNYDER, J. J. "Long-term investing in politicians: Or, give early, give often." Journal of Law and Economics, vol.35, p.15.43, 1992.

WELCH, W. P. "The economics of campaign funds." Public Choice, vol.20, p.83-97. 1975.

POWER, T. J; ZUCCO, C. "Estimating ideology of Brazilian Legislative parties, 1990 . 2005: a research communication." Latin American Research Review, vol. 44, $\mathrm{n}^{\circ} 1$, p.218-246, 2009.

Leany Barreiro Lemos - leanyl@yahoo.com.br Daniel Marcelino - dmsilv@gmail.com João Henrique Pederiva - pederiva@senado.gov.br

Recebido para publicação em junho de 2010. Aprovado para publicação em outubro de 2010. 